\title{
Prosocial Behavior and Big Five-Factor Model of Personality: A Theoretical Review
}

\author{
Aalima Mumtaz Shah ${ }^{1}$, Dr. Touseef Rizvi ${ }^{2}$
}

\section{ABSTRACT}

The manner in which one acts or behaves in response to environment, person or stimulus that is external or internal, covert or overt and voluntary or involuntary is the behavior of an individual. Behavior is determined by his or her personality (is the set of psychological traits and mechanisms with the individual that are organized and relatively enduring and that influences his or her interactions with, and adaptation to, the intra psychic, physical ,and social environments). Personality is determined by various factors, these factors are examined by different researchers and psychologists, various models came out of it, Big Five-Factor Model (Costa \& Mc Crae,1995 ) is one among them .An individual possessing specific traits behave specially in the society. Individuals moving towards people and society when they are in need are performing prosocial behavior (refers to acts that are positively valued by society).In our culture helping others is socially valued. Thus helpful responses are a form of prosocial behavior. Empirical work has been done to examine the relationship of prosocial behavior and personality traits. This paper presents the theoretical review of the relationship between prosocial behavior and Big Five-Factor Model of Personality, from last fifteen years.

\section{Keywords: Personality, Big Five-Factor Model Prosocial Behavior}

Individuals can't live in isolation to live a satisfying life they need others as well, when two or more than two individuals are together they form group, different groups make a society, there exists individual differences, to live in harmony in society one has to help others (prosocial behavior) and others will help them as well. Some people help others because they expect it in future when they are in need of it, while others help with no such expectation (altruism). This behavior is highly determined by individual's characteristics which they carry from one situation to another. Some characteristics of individuals are dynamic and some are consistent, consistent patterns of thoughts, feelings and actions are traits of personality (Zukauskien \& Malinauskien, 2009).Personality psychologists differ in defining traits of personality some view these traits as

\footnotetext{
${ }^{1}$ Research Scholar, Department Of Psychology, University Of Kashmir, Srinagar, India

${ }^{2}$ Sr. Assistant Professor, Department Of Psychology, University Of Kashmir, Srinagar, India

*Responding Author

(C) 2016 Shah A, Rizvi T; licensee IJIP. This is an Open Access Research distributed under the terms of the Creative Commons Attribution License (http://creativecommons.org/licenses/by/2.0), which permits unrestricted use, distribution, and reproduction in any Medium, provided the original work is properly cited.
} 


\section{Prosocial Behavior and Big Five-Factor Model of Personality: A Theoretical Review}

internal characteristics of individual causing them to behave in a particular manner, and others use these terms consistent aspects of behavior (Larsen \& Buss, 2005). Number of models has been proposed to describe these personality traits and Big Five Factor Model is one among them. Empirical research has been conducted to explore the relationship between these five factors of personality and prosocial behavior. This paper reports the theoretical review of this said relationship with respect to gender and age group.

At one or the other time people must be involved in voluntary actions that intended to help or benefit others and at times must take others help when in need, is referred to as prosocial behavior. It includes acts like, comforting, rescuing helping, and sharing. Prosocial behavior is accompanied with psychological and social rewards; it means that individual can benefit in the long run to live in the prosocial society (Afolabi, 2013). Prosocial behavior first became the topic of major interest in social psychology in the 1960's, after seeing the nonresponsive behavior of people (bystanders) in the brutal murder of Katherine "Kitty" Genovese in 1964 (Zukauskien et al., 2009).Since then a broad range of studies have been conducted to explore the perspectives of prosocial behavior.

Scientists from the very beginning observed the prosocial behavior among animal species. Charles Darwin in 1871 stated that rabbits make noise with their hind feet to warn other rabbits who are in danger (Taylor, Peplau, Sears, 2011). This evolutionary perspective of prosocial behavior proposes that helping behavior depends on genetic relatedness, age and reproductive value of help taking individual, this principle of helping is known as kin selection. Another principle in the evolution of prosocial behavior is reciprocity altruism; this principle states that people help to the individuals who share social context that entails a likelihood of future interactions, in which some kind of reciprocity can be anticipated (Aydinli, Bender, \& Chasiotis, 2013).

Scientists who do not support the evolutionary aspect of prosocial behavior argue that social factors are much more important than biological factors. The genetic evolution may help in explaining a few aspects of prosocial behavior such as parents care towards their children, but does not explain the extreme instances of prosocial behavior like helping strangers and acts of generosity as suggested by Donald Campbell (1975) and calls it "social evolution"- historical development of human culture. According to this view, human societies have slowly and selectively evolved skills and beliefs that are beneficial for the group and society as well, so that it has became part of social rules and norms (Taylor et al., 2011).

The other perspective of helping is the psychological approach proposing that reason behind this particular behavior is the learning experiences and emotions. Past experiences of prosocial behavior may make individuals to expect positive outcomes from this behavior, such as social approval, social recognition, financial benefits, and group entry etc. An individual may 


\section{Prosocial Behavior and Big Five-Factor Model of Personality: A Theoretical Review}

experience negative feeling after knowing that the other individual is in need, this personal distress can possibly be relieved helping that individual to fulfill his need. The empathy-altruism hypothesis proposed by Batson states that the reason for this behavior is the identification with the person in need evokes empathic feelings leads to altruistic motivation (going beyond mere reduction of one’s own negative feeling) (Aydinli et al., 2013).

From ancient times role of males are considered protectors, men are more likely to help others that is defined as heroic-saving someone being attacked or being drowned. Since 1904, the Carnegie Hero Fund Commission, yearly, has recognized citizens who voluntarily and knowingly risk their lives for saving others. Among 8,706 only 9 percent were women to receive this award. Men's physical features and body strength may contribute to this sex difference. In mundane settings, men are more likely to help stranger in need, and especially when the requester is female. Women's perform nurturant forms prosocial behavior, such as caring, comforting etc. Research has found that women help their friends more than males do, and give advices to their friends to solve their personal problems. Studies have also revealed that females give social support to others, takes major responsibility for the care of children and aging parents. In other words, men and women specialize in different types of helping behaviors. (Taylor et al., 2011).

Social psychologists were not able to discover a single personality trait that is responsible for this helping behavior, modern research has shown relationship between helping and personality variables such as social approval, group acceptance. Personality researchers on helping behavior have responded to the challenge by finding individual differences in this helping behavior, gathering clues to the network of traits that predispose a person to helping behavior, and to find influence of personality in particular situation (Mayer's, 2002). Studies have been found that out of five traits agreeableness is more strongly related to prosocial behavior (Caprara, Alessandria \& Eisenberg, 2011).And, also trusting, altruistic and trustworthiness has been associated with agreeableness by Costa \&Mc Crae (1992).On the other hand extraversion has been found as an aggregate of two components affiliation (need to have warm personal relationship) and agency (need for being assertive and influential) Costa \&Mc Crae (1992).This indicates that these two components of extraversion can motivate an individual to perform prosocial behavior.

The term personality is often understood in terms of social attractiveness. A good personality is considered to be one who impresses other people and who has the ability to get on well with others. Those who do not possess such ability are said to have relatively poor personality. However, if one considers personality from a scientific point of view, being attractive to others is not a true concept of personality. Psychologists attempt to explain personality as important and relatively stable aspects of behavior. Consider the behavior of an individual, who would behave shyly in different situations and over significant period of time but she may be outgoing with her family and friends. 


\section{Prosocial Behavior and Big Five-Factor Model of Personality: A Theoretical Review}

Most personality theorists explain personality, as including virtually everything about an individual-physical, social, emotional, and mental. Some aspects of personality are observable and some are considered to unobservable. Personality also includes conscious and unconscious aspects of behavior (Ewen, 2010). Trait approach attempts to explain personality and differences between in terms of their personal characteristics, to devise ways of measuring individual differences in personal traits and to use these measures for understanding and predicting a person's behavior. Various psychologists have given their view points on trait approach and many models have been proposed on this approach. Big five factor model is one among them.

One group of researchers has found that big Five traits consistently emerge from factor-analytic research these are as:

(I) Introversion-extraversion (reserved vs. outgoing),

(II) Neuroticism (calm and secure vs. nervous and insecure),

(III) Conscientiousness (lazy and unreliable vs. hard-working and reliable),

(IV) Agreeableness (suspicious and uncooperative vs. trusting and helpful), and

(V) Openness (Conventional vs. creative).

Advocates of this model have given their support that these traits represent the core of personality. The big five traits describe personality aspects that are remarkably consistent in adults as elderly people undergo through many radical changes that may affect these traits. Currently, the Big Five model dominates the landscape of psychological research (McCrea \& Costa 1992; Ewen, 2010)

The most widely used measure using sentence-length item format has been developed by Paul $\mathrm{T}$ Costa and Robert R. McCrae. It's called the NEO-PI-R: the neuroticism-extraversion-openness (NEO) Personality Inventory (PI) Revised (R) (Costa \& McCrae, 1989). Sample items from the NEO-PI-R are neuroticism (N): I have frequent mood swings; extraversion (E) :I don't find it easy to take charge of a situation(reverse scored); openness (O): I enjoy trying new and foreign foods; Agreeableness (A): most people I know like me; and conscientiousness (C): I keep my belongings neat and clean.

In summary, we can conclude that prosocial behavior is related to big five personality traits most studies support agreeableness and extraversion traits of personality as associated with prosocial behavior. Males perform prosocially in one condition and the females on the other. Personality is not a stable process rather than it is relatively dynamic, it relatively changes from one period of life to the other. Some traits of personality such as neuroticism, openness to experience and agreeableness are mostly found in females then in males (Costa, Terracciano, and McCrae 2001). 


\section{PROSOCIAL BEHAVIOR AND GENDER}

Who help others out more, men or women? We probably think that women are more likely to do prosocial deeds. Yoleri and Seven (2014) evaluate effect sex differences on prosocial behavior of preschool children and found that gender cause statistically significant difference in the prosocial behavior scores, as rated by teachers. Accordingly, girls score high points on prosocial behavior. Mesch, Brown, Moore, and Hayat (2011) examines gender differences on charitable giving by exploring eight mechanisms for giving developed by Bekkers and Wiepking, two national data sets were used in this study. Results for both data sets indicate significant gender differences in motives, as well as probability of giving and amount given where females score high on empathic concern, principle of care and giving amount than men. Gregory, Haeurseman, Jade, Rijsdik (2009) conducted a longitudinal family study to assess the genetic and environmental influence upon prosocial behavior in adolescence, and found adolescent females were significantly more prosocial than males. Piper and schnepf (2008) examines gender differences in charitable giving in Great Britain and find that women are significantly more likely than men to give charities. Zimmer-Gemback, Geiger and Crick (2005) conducted prospective study on middle school students to examine the bidirectional associations between children's relation with schoolmates and prosocial behavior. No gender difference was found in aggression at grade 3 and female were found more relational aggressive and boys more physical aggressive at grade 6 . Females were found more prosocial and preferred by peers than males. Lots of studies have done on whether men or women help others out more and they have found different results depending on the situation. Women are more likely to offer nurturing help; men on the other hand, are likely to help out in chivalrous ways (stepping to defend a girl from being harassed). Women score higher on most measures of traits, motivation, and values that predict helping others and women are more likely to help family and friends, but in the institutional helping behaviors of volunteering and charitable giving gender differences are small as argued by Einolf (2011). Eisenberg, Cumberland, Guthrie, Murphy and Shepard (2010) found women more prosocial in comparison with men in sympathy and perspective taking whereas no difference was found in self reported helping. Considering gender stereotypes, the differences in girls and boys isn't very pronounced. Afolabi and Idowu (2014) study the influence of gender, spiritual involvement/belief and emotional stability on prosocial behavior among some Nigerian Drivers. The study revealed that gender doesn't have significant effect on prosocial behavior. Kumru (2012) found significant gender differences in a study which was conducted to assess the moral reasoning \& prosocial behavior but the effect was small. Individual differences should also be considered in prosocial behavior. Afolabi (2014) conducted a study to assess psychological predictors of prosocial behavior. For this purpose a sample of 440 students was taken from two Nigerian Universities, (230 males \&210 females) ranging age from19 to 27 yrs. Five measures were used in this study (a) Demographic Measures,(b) Prosocial Behavior Scale (Afolabi), (perceived Social Exclusion Scale. The result show that there is significant relationship among the variables of study, besides there is significant individual contribution to prosocial behavior. It was also found that respondents residing in a village were more prosocial than those in a city.

(c) The International Journal of Indian Psychology, ISSN 2348-5396 (e) | ISSN: 2349-3429 (p) | 165 


\section{PROSOCIAL BEHAVIOR IN LIFE COURSE}

Most children behave more prosocially as they grow older. This behavior begins with the childhood from age 12-18 months when they begin to present and give their toys to their parents and caretakers, without being reinforced. Child begins with instrumental help to empathic help as its moral and cognitive development took place. Eisenberg et.al (2010) conducted a research to examine the age changes in prosocial responding and moral reasoning in adolescence and early adulthood. It was found that some aspects of prosocial behavior functioning increased with maturity from adolescence to adulthood. Sze and Gyurak (2012) assessed emotional empathy and prosocial behavior in older, middle-aged and young adults. It was found that emotional empathy and prosocial behavior increase with age. The changes are not drastic but are relative that can be assessed at one time period of the life in some situations and can't be assessed at the other time period. Yoleri et.al (2014) evaluates the effect of age on prosocial behavior of preschool children. The result of the study revealed that age as a variable did not cause a significant difference in the prosocial behavior scores of the children. Kumru et al. (2012) conducted a study to assess the moral reasoning \& prosocial behavior of early \&middle adolescence in association with age. Results showed significant differences in age on prosocial moral reasoning \&behavior but the effect were small.

\section{BIG FIVE PERSONALITY TRAITS AND GENDER}

Men and women have obviously different biological roles but how much they differ in their personality is an interesting question, that how men and women differ in the ways in which they think, feel, and behave. Traits are the consistent patterns of thoughts, feelings, motives and behaviors that a person exhibit across situations. Gender differences on personality traits characterized in terms of which gender score high on which trait. Costa, Terracciano, and McCrae (2001) assess the gender differences on personality traits and found that women show higher levels of neuroticism, openness to experience and agreeableness. Weisberg, Deyoung, Hirsh (2011) investigates gender differences in personality traits and found that women reported higher at Extraversion, Agreeableness, and Neuroticism scores than men. Neuroticism and agreeableness were found consistent in college and older women than men in a study conducted by Chapman, Duberstein, Sorenson, and Lyness (2008). Rahmani and Lavasani (2012) investigates the gender differences in personality traits on undergraduate students and found that girls score high on Openness to Experience and Agreeableness as compared boys. Studies quoted in this paper on gender differences show varied results but the trait agreeableness is found mostly in females.

\section{BIG FIVE PERSONALITY TRAITS AND AGE DIFFERENCES}

Allport define personality as "the dynamic organization within the individual of the psychophysical systems that determine his characteristic feature and thought.” It is evident from this definition that personality is not stable rather it is changing because of psychological and physical changes within the individual. Lots of studies have been conducted to investigate 


\section{Prosocial Behavior and Big Five-Factor Model of Personality: A Theoretical Review}

whether personality is consistent or dynamic. Dunnellon and Lucas (2008) attempted to examine the age differences in all of the Big Five Personality Traits from age 16 to the mid 80's using large sample from two countries (Britain and Germany).the result revealed that extraversion and openness are negatively associated with age whereas agreeableness are positively associated with age and mean levels of conscientiousness were found highest in middle age. Rantenan, Metsapelto, Feldt, Pulkkinen, and Kokko (2007) investigated the stability of Big Five Traits in adulthood from age 33 to 42 . Longitudinal study on personality and social development was conducted on 89 men and 103 women. Results found from this study show that mean-level of neuroticism decreased whereas, mean-level of Extraversion, Openness to experience, Agreeableness, Conscientiousness increased from 33 to42 years of age. The results from the study also reveal that Neuroticism and Extraversion were more stable in men than in women whereas Openness to Experience, Agreeableness and Conscientiousness were as stable in men as in women. Roberts and Vecchio (2000) used Meta analytic technique to test whether trait consistency maximizes and stabilizes at specific period of life. The results show that trait consistency increase with age from childhood to adulthood.

\section{BIG FIVE TRAITS OF PERSONALITY AND PROSOCIAL BEHAVIOR}

Personality has significant relation with prosocial behavior. What type of personality an individual has can help to predict whether the individual is prosocial being or not? Psychologist has done much work on this aspect of behavior and has found such traits that are mostly related to prosocial behavior. Swickert, Abushanab, Bise and Szer (2014) tested whether Conscientiousness influences verbal responses to a help-eliciting prime as well as whether it moderated the influence of this type of prime in the prediction of self-reported prosocial behavior. Benjamin E, Andreas, Zettler and Ingo (2014) investigate the relation of personality traits and prosocial behavior and found that agreeableness a personality trait account for prosocial behavior. Afolabi (2013) conducted a cross-sectional survey to assess the prosocial (PSB) behavior among undergraduates in Nigeria to investigate the influence of five personality factors (FFB) on prosocial behavior. The research showed that there was significant relationship between the variables of study. The first step in the hierarchical regression showed that the independent and joint contribution of age, gender, religion and educational level on PSB were not significant, the FFB didn't have significant independent and joint contribution on PSB except for conscientiousness. Mlcak (2012) studied the five-factor model of personality, aspects of prosocial behavior and empathic tendencies in a sample of high school and university students $(\mathrm{N}=1454)$ in contexts of gender, study orientation and volunteering experience. It has been found that female students show higher levels of neuroticism, agreeableness, altruism and empathy tendencies and lower level of public behavior than male students. Helping professions respondents demonstrate higher levels of openness to experience, anonymous behavior, altruism, behavior in crisis, empathic concern and perspective taking than respondents in technical and economic professions. Respondents with volunteering experience demonstrate higher levels of extraversion, openness to experience, conscientiousness, anonymous behavior, and emotional 


\section{Prosocial Behavior and Big Five-Factor Model of Personality: A Theoretical Review}

behavior, behavior in crisis, empathic concern, perspective taking, empathic fantasy and lower level of personal distress than respondents without this experience. It has been simultaneously found that the dimensions of five-factor model reflect prosocial and empathic tendencies latently and diffusion ally. The results from the study reveal that those high on conscientiousness trait report greater helping. . The trait agreeableness has been found to be strongly linked to prosocial behaviors (Caprara et al. 2011). Zukauskiene and Malinauskien (2009) investigate the relationship between youth prosocial orientation, and personal values in a sample of Lithuanian adolescents. The sample taken was adolescents who were engaged in community and school life and those who were not. The study show significant results among the groups in terms of personality traits and values, where very involved and involved adolescents were characterized by more pronounced traits in extraversion, openness to experience and agreeableness, while conscientiousness was significantly higher in adolescents who were very involved. Carlo, Okun, Knight, and Guzman (2005) studied interplay of personality traits and motives on volunteering: agreeableness: extraversion and prosocial value motivation. The results from the study revealed that agreeableness and extraversion were more strongly related to volunteerism behavior than conscientiousness, neuroticism, and openness to experience, prosocial value motivation partially/fully mediated the relations between agreeableness/extraversion and volunteerism and extraversion and agreeableness interacted to influence prosocial value motive, which in turn, predicted volunteerism. The literature reviewed in relation to personality trait and prosocial behavior in this paper has given varied results, mostly agreeableness, extraversion, and conscientiousness traits have been found in prosocial people. So that it can be concluded that prosocial behavior is not determined by a single trait rather is influenced by many factors that may be genetic and environmental as well.

\section{FUTURE DIRECTIONS}

Prosocial behavior has long history in psychology in general and social psychology in particular. Our aim should be to inculcate prosocial behavior in children so that we may get a developed society. It can be done in schools and at homes as well by giving rewards on sharing, caring, and helping others. More researches should be conducted to explore other factors that are responsible for the development of prosocial behavior.

Most people outside the Kashmir think that this place is full of antisocial elements but the people of Kashmir have proved themselves to be prosocial in various situations .whether we talk about last year's flood situation or at the period of 90's. More and more researches should be done to change the thinking of other people that it is not an antisocial place rather than a prosocial place.

\section{Acknowledgments}

The author appreciates all those who participated in the study and helped to facilitate the research process. 


\section{Conflict of Interests}

The author declared no conflict of interests.

\section{REFERENCES}

Afolabi, O. A. \& Idowu, E. O. (2014). Influence of gender, spiritual involvement/belief and emotional stability on prosocial behavior among some Nigerian drivers. Canadian Social Science, $10(1)$.

Caprara, G. V., Alessandri, G., \& Eisenberg, N. (2011). Prosociality: The contribution of traits, values, and self-efficacy beliefs. Journal of Personality and Social Psychology.

Costa, P., Mc.Crae. R., \& Antonio, T. (2001). Gender difference in personality traits across cultures. Journal of Personality and Social Psychology, 81(2), 322-331.

Chapman, B. P., Duberstein, P. R., Sorenson, S. \& Lyness, J. M. (2007). Gender differences in Five Factor model of personality traits in an elderly cohort extension of robust and surprising findings to an older generation. Pers Individ Dif, 43(06),1594-1603. doi: 10.1016/j.paid.2007.04.028

Dunnellon, M. B. \& Lucas, R. E. (2008). Age differences in the Big Five across the life span: Evidence from two national samples. Psychol Aging, 23(3), 558-66. doi: $10.1037 / \mathrm{a} 0012897$

Einolf, J. C. (2011). Gender differences in the correlates of volunteering and charitable giving. Nonprofit and voluntary sector Quarterly, 40(6), 1092-1112.

Eisenberg, N., Guthrie, I. K., Cumberland, A., Murphy, B. C., Shepard, S. A., Zhou, Q., \& Carlo, G. (2002). Prosocial development in early adulthood: A longitudinal study. Journal of Personality and Social Psychology, 82(6), 993. Retrieved from: http://psycnet.apa.org/journals/psp/82/6/993/

Franzoi, I. S. (2003). Social Psychology ( $3^{\text {rd }}$ ed.). NewYork. MC Graw Hill Companies.

Gregory, A. M., Light-Haeurseman, Jade \& Rijsdik (2009). Behavioral genetic analysis of prosocial behavior in adolescent. Developmental Science, 12, 165-174.

Lehdonvirta, M., Lehdonvirta, V. \& Baba, A. (2011). Prosocial behaviour in avatar-mediated interaction: The influence of character gender on material versus emotional help-giving. On the Horizon, 19(3), 165-173.

Lukacikova, M. (2011). Prosocial behavior of adolescents in school and after school environment. Education and Healthcare,21. 211-215.

Meschi, D. J., Brown, M. S., Moore, Z. I., \& Hayat, A. D. (2011) Gender differences in charitable giving. International Journal of Nonprofit and Voluntary Sector Marketing. doi: $10.1002 / n v s m$

Myers, D. G. (2002). Social Psychology (7 $7^{\text {th }}$ ed.). NewYork.Tata MC Graw Hills.

Knafo, A., \& Plomin, R. (2006). Prosocial behavior from early to middle childhood: Genetic and environmental influences on stability and change. Developmental Psychology, 42(5), 771-786. 
Penner, L. A., Dovidio, J. F., Jane, A., Piliavin, J. A. \& Schroeder, D. A. (2004). Prosocial behavior: Multilevel perspectives. Annu. Rev. Psychol., 56(14), 14.8-14.28. doi: 10.1146/annurev.psych.56.091103.070141

Rahmani, S. \& Lavasani, M. G. (2012).Gender differences in Five Factor model and personality and sensation seeking. Social and Behavioral Sciences, 26, 2906-2911. doi:10.1016/j.sbspro.2012.05.587

Weisberg,Y. J., Deyoung, C. G. \& Hirsh, J. B. (2011).Gender differences in personality across the ten aspects of the Big Five. Personality Science and Individual Differences, 2, doi: 10.3389/fpsyg.2011.00178

Yoleri, S. \& Seven, S. (2014). Analyzing effect of age and sex differences on prosocial behavior of preschool children. International Journal of Social Science, 29, 261-270. doi:10.9761/JASSS2425

Taylor, S. E., Peplay, L. A., \& Sears, D. O. (2011). Social Psychology $\left(12^{\text {th }}\right.$ ed.). India: Dorling Kindersley Pvt. Ltd

Zimmer-Gemback, M. J., Geiger, T. C., \& Crick, N. R. (2005). Relational and physical aggression, prosocial behavior, and peer relations gender moderation and bidirectional associations. The Journal of Early Adolescence, 25(4), 421-452. doi: $10.1177 / 0272431605279841$

How to cite this article: Shah A, Rizvi T (2016), Prosocial Behavior and Big Five-Factor Model of Personality: A Theoretical Review, International Journal of Indian Psychology, Volume 4, Issue 1, No. 80, ISSN:2348-5396 (e), ISSN:2349-3429 (p), DIP:18.01.117/20160401, ISBN:9781-365-57867-0 